\title{
De entrave à potencialidade: Análise e diretrizes ecológicas para o Parque do Povo e do Córrego do Veado em Presidente Prudente- SP
}

From obstacle to potentiality: Analysis and ecological guidelines for the Parque do Povo and Córrego do Veado in Presidente Prudente-SP

De obstáculo a la potencialidad: Análisis y directrices ecológicas para el Parque do Povo y el Córrego do Veado en Presidente Prudente-SP

Talita Rezende Torcato Pereira Mestranda do Programa de Pós-Graduação Associado em Arquitetura e Urbanismo UEM/UEL, Brasil talita.rtp@gmail.com

Fellipe Sambinelli Luiz

Graduado em Arquitetura e Urbanismo pela UNOESTE , Brasil fellipeluiz@msn.com

Karin Schwabe Meneguetti Doutora em Arquitetura e Urbanismo pela USP. Professora do Programa de Pós-Graduação Associado em Arquitetura e Urbanismo UEM-UEL, Brasil ksmeneguetti@uem.br 
De entrave à potencialidade: Análise e diretrizes ecológicas para do Parque do Povo e do Córrego do Veado em Presidente Prudente- SP RESUMO

$\mathrm{O}$ descuido com o meio ambiente e a falta de planejamento ambiental integrado com o planejamento urbano promovem desequilíbrios ambientais e, até mesmo, desastres naturais. As cidades atuais têm promovido o desenvolvimento urbano desassociado das questões ambientais, tratando sua base natural como entrave para o crescimento. Desta forma, o presente artigo tem como finalidade analisar a situação atual do Parque do Povo e o Córrego do Veado como possíveis potencializadores para a formação de uma estrutura ecológica para a cidade de Presidente Prudente-SP. Busca-se entender qual a importância de ambos para a cidade, seja no seu tipo de ocupação ou como são tratados na questão na visão do planejamento ambiental. Por meio de levantamentos bibliográficos, visitas in loco, e discussões, foi constatado a necessidade de propostas alternativas para o Parque do Povo e para o córrego do Veado, propagando-as para a cidade e configurando-como ponto de partida para a implantação de uma estrutura ecológica para a cidade de Presidente Prudente-SP. Apresentam-se diretrizes projetuais para que a área possa interagir com os processos naturais e prevenir inundações que já se tornaram frequentes.

PALAVRAS-CHAVE: Córrego Veado; Estrutura Ecológica; Parque do Povo; Presidente Prudente, SP.

From obstacle to potentiality: Analysis and guidelines for implementation of an ecological structure for the Parque do Povo and Córrego do Veado in Presidente Prudente- SP

\section{ABSTRACT}

The neglect of the environment and the lack of integrated environmental planning with urban planning promote environmental imbalances and even natural disasters. Today's cities have fostered urban development disassociated with environmental issues, treating their natural base as an obstacle to growth. Thus, the purpose of this article is to analyze the current situation of the Parque do Povo and the Córrego do Veado as potential enhancers for the formation of an ecological structure for the city of Presidente Prudente-SP. It seeks to understand the importance of both of them for the city, whether in your type of occupation or how they are treated in the perspective of environmental planning. By bibliographical surveys, on-site visits, and discussions, it was verified the need for alternative proposals for the Parque do Povo and for the Córrego do Veado propagating them to the city and setting it up as the starting point for the implementation of an ecological structure for the city of Presidente Prudente-SP. Project guidelines are presented so that the area can interact with natural processes and prevent floods that have become frequent.

KEY WORDS: Córrego Veado; Ecological Structure; Parque do Povo; Presidente Prudente,SP

De obstáculo a la potencialidad: análisis y directrices para implantación de una estructura ecológica para el Parque do Povo y el Córrego do Veado en Presidente Prudente- SP

\section{RESUMEN}

El descuido con el medio ambiente y la falta de planificación ambiental integrada con la planificación urbana promueven desequilibrios ambientales e incluso desastres naturales. Las ciudades actuales han promovido el desarrollo urbano desasociado de las cuestiones ambientales, tratando su base natural como obstáculo para el crecimiento. De esta forma, el presente artículo tiene como finalidad analizar la situación actual del Parque do Povo y el Córrego do Veado como posibles potencializadores para la formación de una estructura ecológica para la ciudad de Presidente Prudente-SP. Se busca entender cuál es la importancia de ambos para la ciudad, sea en su tipo de ocupación o como son tratados en la cuestión en la visión de la planificación ambiental. Por medio de encuestas bibliográficas, visitas in loco, y discusiones, se constató la necesidad de propuestas alternativas para el Parque do Povo y para Córrego del Veado, propagándolas a la ciudad y configurándolo como punto de partida para la implantación de una ciudad La estructura ecológica para la ciudad de Presidente Prudente-SP. Se presentan directrices proyectivas para que el área pueda interactuar con los procesos naturales y prevenir inundaciones que ya se han vuelto frecuentes.

PALABRAS CHAVES: Córrego Veado; Estructura Ecológica; Parque del Povo; Presidente Prudente, SP. 


\section{INTRODUÇÃO}

$\mathrm{Na}$ composição da maioria das cidades brasileiras observa-se uma conturbada relação entre urbanização e a preservação dos recursos naturais. Como explicita McHarg (1969), a natureza é tratada, muitas vezes, como um inimigo que o ser humano necessita dominar para poder se desenvolver, vista como empecilho no desenvolvimento territorial e econômico de um determinado local. Com essa relação conflituosa entre a sociedade, natureza e o espaço urbano, o processo de urbanização torna-se resultado do "não cumprimento das leis e normas que regem o planejamento urbano e ambiental, quando estes são existentes. Essa forma de crescimento desconsidera a dinâmica dos processos naturais (geomorfológicos, pedológicos, hídricos entre outros), que associados à falta de infraestrutura básica agravam o quadro ambiental das cidades." (PEDRO; NUNES, 2012, p.87).

Quando a urbanização está desassociada das questões ambientes e paisagísticas, os rios e córregos são lembrados apenas como barreiras físicas ou lugares insalubres que, em dias de fortes chuvas, transbordam e causam prejuízos à cidade (Francisco, 2012, p.5). É possível ver a reprodução desta situação de desenvolvimento urbano em Presidente Prudente, SP, especificamente no Córrego do Veado, objeto deste artigo.

\section{OBJETIVOS}

1.1 OBJETIVO GERAL

- Identificar problemas e potencialidades do Parque do Povo e da microbacia do Córrego do Veado localizado na cidade de Presidente Prudente, São Paulo.

\subsection{OBJETIVOS ESPECÍFICOS}

- Discutir sobre a realidade a respeito do Córrego Veado e o Parque do povo com a cidade de Presidente Prudente e como ele pode se aliar à questão de melhoria ambiental para a cidade e os moradores;

- Avaliar a situação atual a respeito das condições em que o Córrego Veado se encontra;

- Propor diretrizes que possam auxiliar na melhoria ambiental do entorno do Córrego Veado e para a cidade.

\section{METODOLOGIA/MÉTODO DE ANÁLISE}

Para a realização deste trabalho foram adotados os seguintes métodos de análise: revisão bibliográfica; levantamento histórico da cidade; levantamento histórico e a respeito do Córrego Veado e os planos diretos vigentes para servir de base para as diretrizes propostas.

\section{RESULTADOS}

\section{A cidade e sua base biofísica}

Presidente Prudente localiza-se na região sudeste do Brasil, no interior do Estado de São Paulo. Segundo Francisco e Ferrarezi (2014), a cidade se desenvolveu a partir da linha férrea em sentido oeste, devido esta ser uma área com relevo menos acidentado. 


\section{Periádica Eletrânica \\ Fórum Ambiental}

De acordo com o IBGE, a cidade possuía em 2010 uma população de mais de 200 mil habitantes. O município está inserido em duas bacias hidrográficas, sendo: a do Rio do Peixe, responsável pelo abastecimento da cidade e a Bacia do rio Santo Anastácio, onde se encontra a maior porção da cidade e nosso objeto de estudo. Esta última é composta pelos Córregos Saltinho, Água Boscoli, Bacarin e Colônia Mineira, que se juntam ao córrego do Veado e definem a microbacia do Córrego do Veado, conforme Figura 1.

Figura 1: Mapa das bacias dentro do Perímetro Urbano e localização do Parque do Povo em relação a elas.

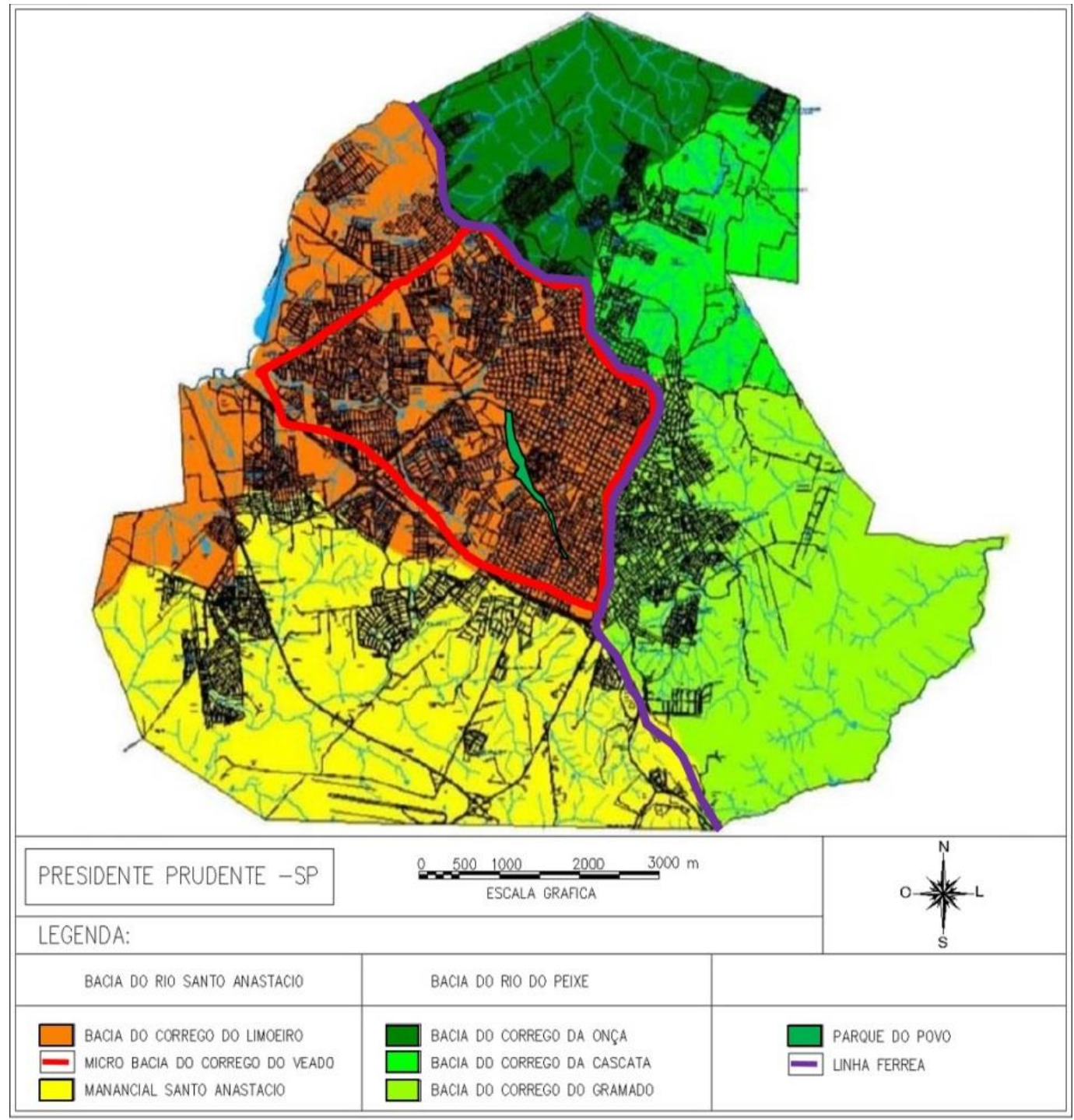

Fonte: RELATÓRIO PLANO DE DRENAGEM URBANA COM ALTERAÇÃO DOS AUTORES, 2016.

Com a necessidade de desenvolvimento, a urbanização da cidade se deparou com algumas barreiras: a linha férrea, impedindo o crescimento a leste, e o fundo de vale do córrego do Veado, impedindo o crescimento ao sul e a oeste do Córrego Colina Mineiro (FRANSCISCO; 
FERRAREZI, 2014).Após isto, o córrego do Veado passou por conturbados processos de ações descontinuadas e não planejadas (Figura 2), causando muitos impactos negativos, como, por exemplo, sua completa retificação através de placas desde as bordas até o fundo do canal, mudando sua forma e curso. Pedro e Nunes (2012).

Figura 2: Córrego do Veado atualmente

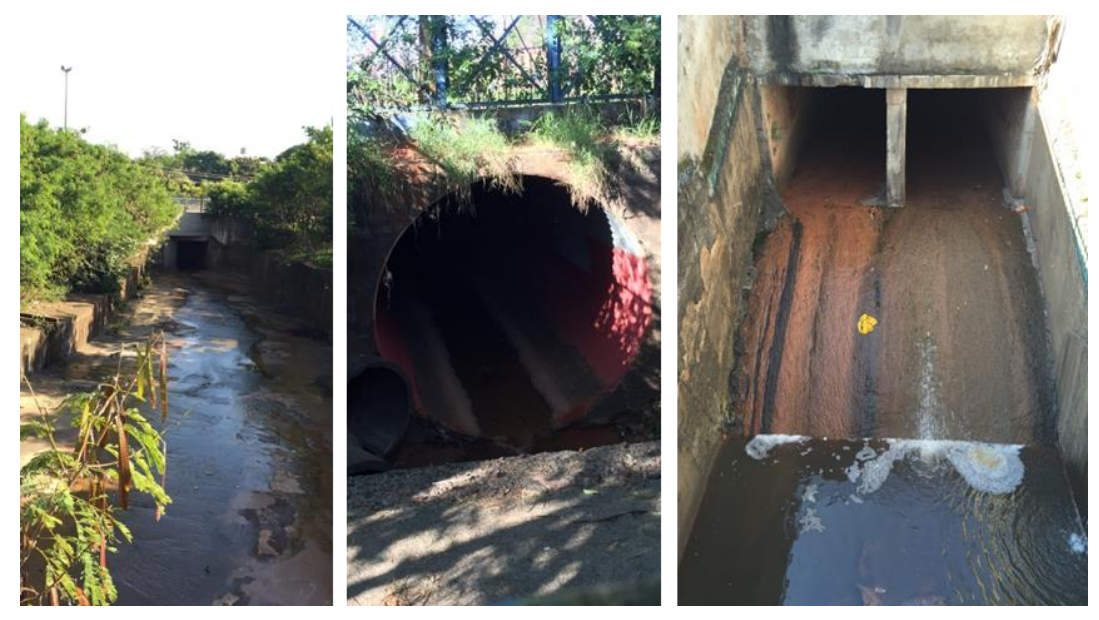

Fonte: FOTOS DOS AUTORES, 2016.

No final da década de 1970, foi iniciado um processo de canalização dos córregos do Bacarin, Bôscoli e, principalmente, o do Veado, financiado pelo projeto CURA ${ }^{1}$ teve como principal finalidade a valorização da área onde seria implantado o Parque do Povo (BORTOLO, 2012). Esta ação desconsiderou diversos atributos fisiográficos, como a questão da drenagem urbana, a capacidade de saturação hídrica do material de aterro, altas precipitações pluviométricas nas épocas chuvosas, gerando assim, uma área suscetível a inundações (Pedro e Nunes, 2012).

\section{O Parque do Povo}

O Parque do Povo foi implantado por meio de uma parceria político privada com finalidade de “'reurbanização' de uma área considerada degradada". Para isto o projeto previa a implantação de duas vias de trânsito rápido que fariam a delimitação de uma ampla área de lazer e recreação, composta por piscinas olímpicas, quadras poliesportivas, ciclódromo, pista de atletismo, de aeromodelismo e quiosques, além de áreas livres vegetadas. (Bortolo, 2012, p.57-58 apud, HORA 1991) Esta melhoria justificava a canalização do Córrego do Veado .

O Parque do Povo possui fluxo intenso e diversificado (Figura 3), em dias de eventos e grande movimentação. É observado que as faixas etárias que mais utilizam o Parque são compostas de adolescentes e idosos, devido aos mobiliários para exercícios ao ar livre e grandes espaços abertos que promovem a troca de informações e um local de convivência.

\footnotetext{
${ }^{1}$ Segundo Francisco (2012, p.6 apud HORA 2001), o projeto CURA (projeto de Comunidade
} 


\section{da Alta Paulista}

Figura 3: Parque do povo atualmente
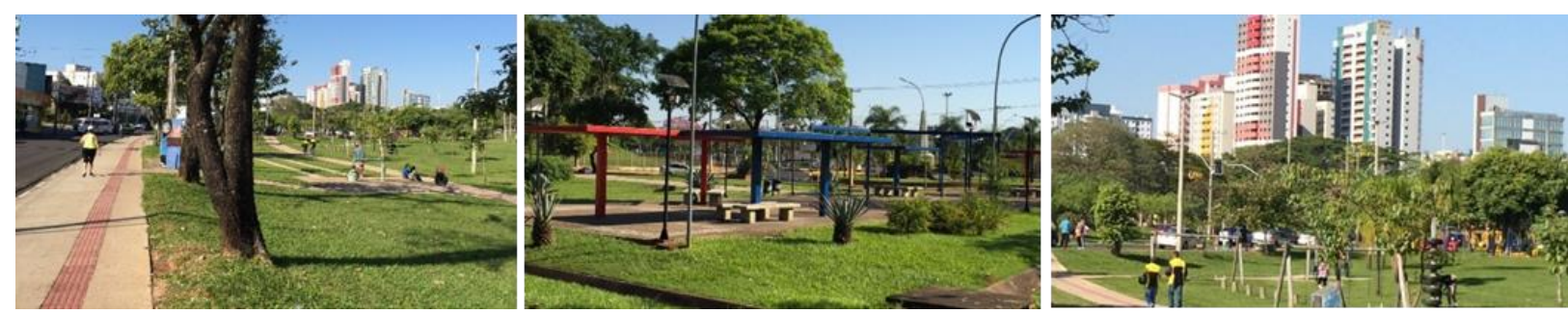

Fonte: FOTOS DOS AUTORES, 2016.

Apesar do projeto do parque ser criticado por falta de uma visão global, ele atende às suas funções de lazer e recreação. A grande problemática, no entanto, é a frequência com que ocorrem alagamentos nas épocas de grandes chuvas. Apesar de contar com grande permeabilidade, o parque fica no centro da microbacia, em uma das cotas mais baixas da cidade (Figura 4), onde estava a calha do rio. O projeto do parque não levou em consideração esta contribuição das águas pluviais. E o seu entorno, atualmente é totalmente edificado com poucos espaços livres, que pouco contribuem com a infiltração das águas pluviais. 
Figura 4: Mapa de níveis, córregos, limites da situação atual da cidade.

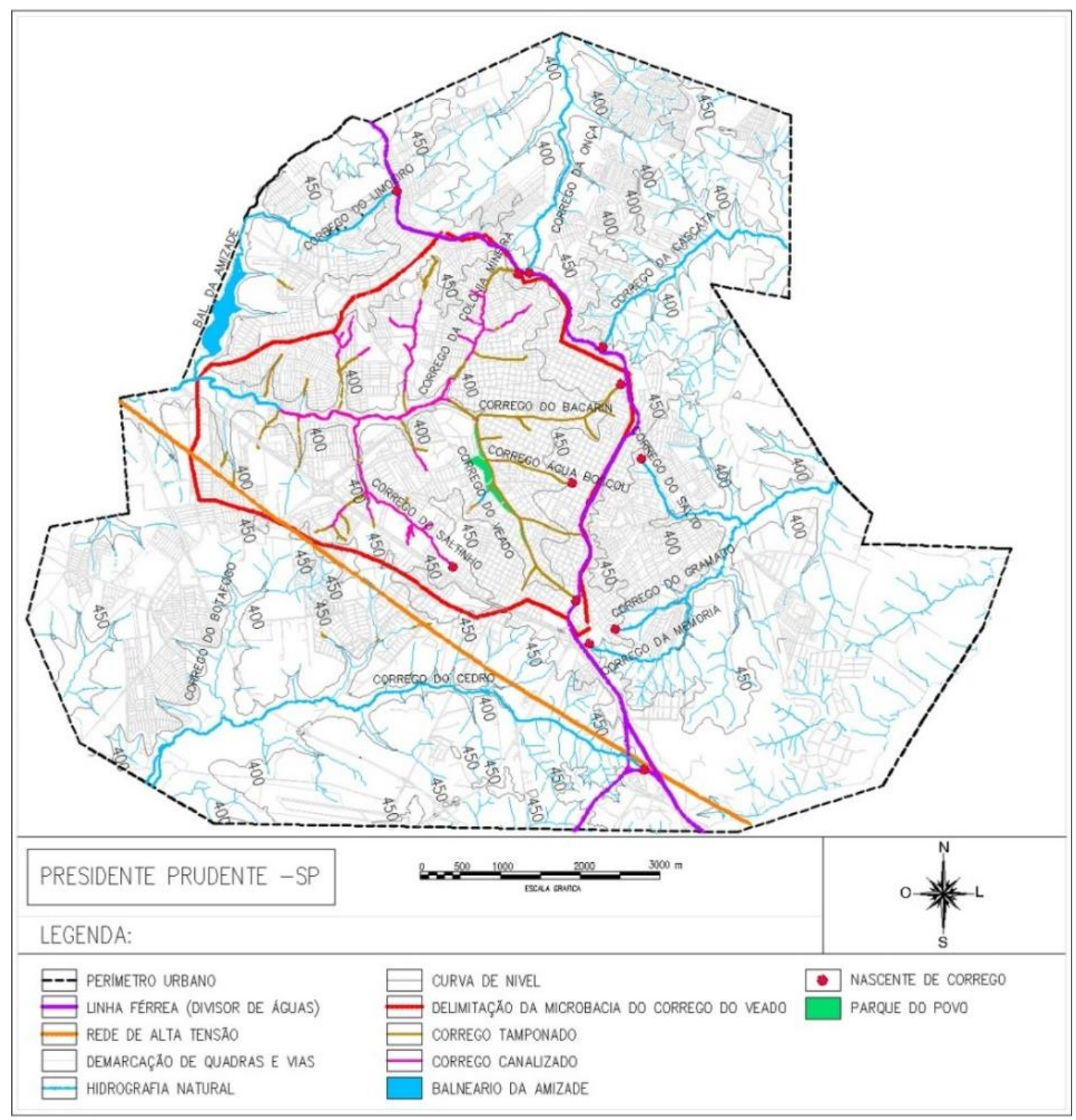

Fonte: ORGANIZADO PELOS AUTORES, 2016. Base: PLANO DE AGUAS PLUVIAIS DE PRESIDENTE PRUDENTE, 2010.

\section{Potencialidades}

A estrutura ecológica atua como importante conector entre os elementos biofísicos da cidade. Ela é a integradora de um conjunto de ações que visam promover a sustentabilidade. Assim, de acordo com MENEGUETTI (2009, p.57)

“A estrutura ecológica enfatiza a importância dos espaços abertos e verdes como partes de sistemas interconectados que são protegidos e manejados para os benefícios ecológicos que eles provêm. A estrutura ecológica implica em que espaços verdades e sistemas naturais devem ser ativamente protegidos, manejados e, em alguns casos, restaurados".

Partindo desse pressuposto, propõe-se neste trabalho a implementação de diretrizes que possam nortear a implantação de uma estrutura ecológica na cidade de Presidente Prudente 


\section{Periádica Eletrânica

partindo do Parque do Povo. Para isto, foram levantadas as potencialidades locais, as quais permitiram a elaboração de propostas conforme a Figura5, que serão descritas ao longo do texto.

Figura 5: Mapa atual com propostas de manchas e de áreas favoráveis a inundações

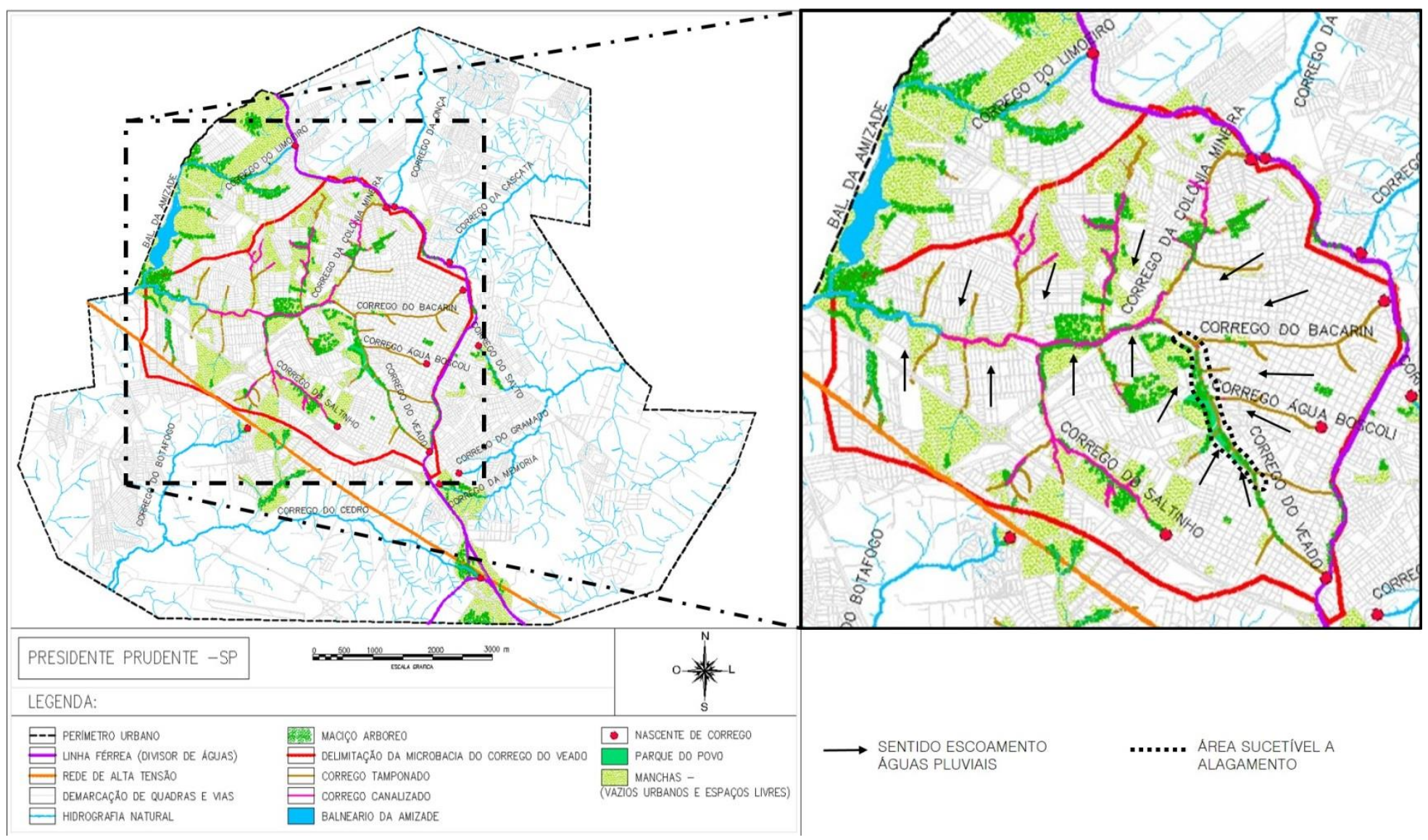

Fonte: ORGANIZADO PELOS AUTORES, 2016. Base: PLANO DE AGUAS PLUVIAIS DE PRESIDENTE PRUDENTE, 2010.

Destacam-se as seguintes potencialidades: áreas vegetadas existentes no perímetro urbano que se caracterizam por manchas dispersas; rios e córregos canalizados e/ou tamponados com sua área e seu entorno com permeabilidades muito baixas e que permitem a sua renaturalização.

As áreas denominadas como manchas são "elementos relativamente homogêneos que diferem do entorno, podem variar em formas e padrões", e tem sua importância porque "fornecem serviços ambientais pela alta permeabilidade do solo e presença de grandes áreas livres, vegetadas ou não (Meneguetti, 2009, p.127). Estas manchas são pontos cruciais na estrutura ora proposta, por exercerem serviços ambientais como: proteção dos cursos d'água e garantia da sua qualidade, habitat de diversas espécies, controle do microclima, além de conterem a erosão e assoreamento (Pellegrino, 2000, p.172). 


\section{Periádica Eletrânica \\ Fórum Ambiental}

da Alta Paulista

Volume 13, Número 07, 2017

A partir da análise das potencialidades identificadas, partiu-se para a elaboração de quatro estratégias que auxiliarão nas diretrizes projetuais, conforme o mapa geral apresentado na Figura 6.

Figura 6: mapa geral de diretrizes

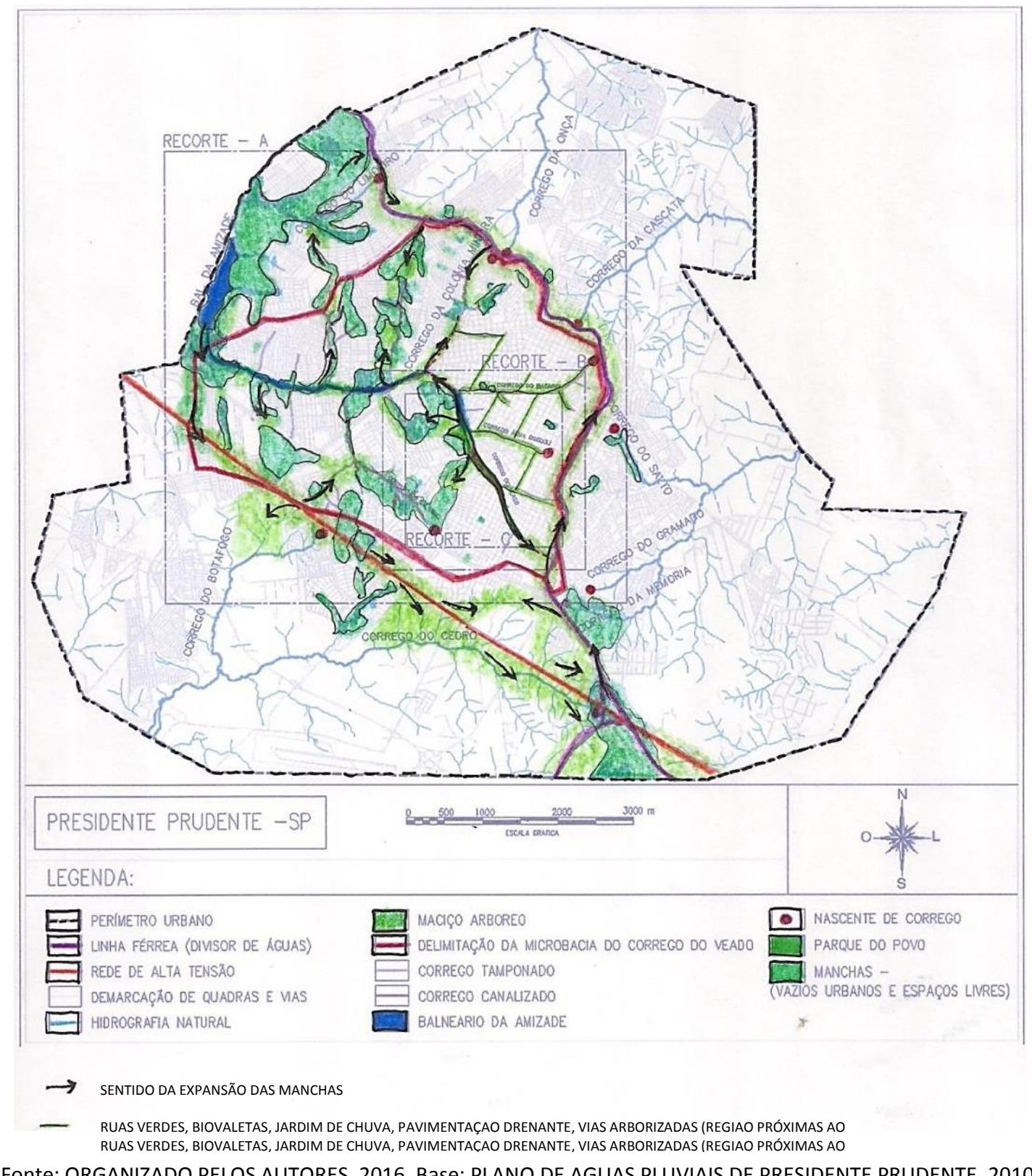

\section{a) Conexões - Parque do Povo}

O Parque do Povo será o estruturador inicial para elaboração de diretrizes de uma estrutura ecológica para a cidade e atuará como corredor verde. Os corredores verdes são elementos lineares e tem função primordial conectar fragmentos de verdes, equipamentos e funções, 
mas, além disso, eles atuam, mas são reguladores da manutenção da biodiversidade, incrementam os espaços de recreação e cultura, proteção dos cursos d'água. (PELLEGRINO ET. AL, 2012.)

A partir do parque, foram propostas conexões viárias com caráter ambiental que permitam a ligação do Parque do Povo a todas as áreas verdes, parques, praças e áreas públicas existentes da cidade. Como por exemplo, as ligações do parque até a UNESP ${ }^{2}$, ao Centro Olímpico, ligação até a Cidade da Criança e ao Balneário da Amizade, localizado na porção noroeste da cidade. Conforme observado no mapa (Figura 7), estas conexões serão realizadas através de ruas arborizadas, ciclovias, pistas de caminhadas.

Figura 7: mapa geral das conexões

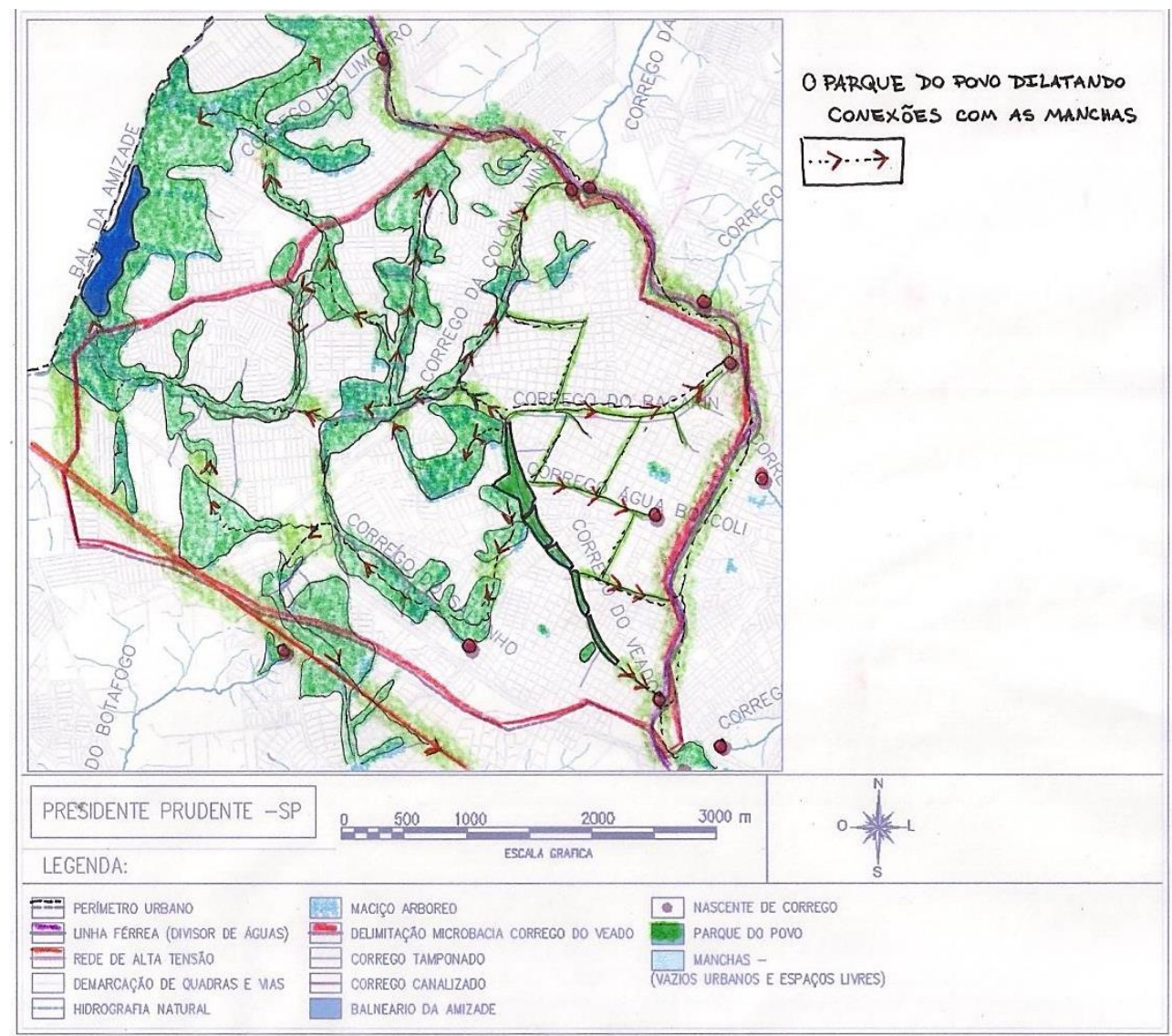

Fonte: ORGANIZADO PELOS AUTORES, 2016. Base: PLANO DE AGUAS PLUVIAIS DE PRESIDENTE PRUDENTE, 2010.

A arborização das ruas tem papel fundamental para estabelecer conexões ecológicas entre as diversas manchas e também para a abrigar diversidade biológica.

A proposta da adoção de ruas verdes que, segundo Meneguetti (2009) possui importância dupla na complementação da estrutura ecológica, pois além de promover as conexões que, no presente artigo tem função de ligação do parque às demais áreas citadas anteriormente-,

\footnotetext{
${ }^{2}$ Universidade Estadual Paulista
} 
também são responsáveis na função ambiental, melhorando a captação e filtragem de águas pluviais que serão encaminhadas ao corpo hídrico do município (figura 8).

As ciclovias e pistas de caminhadas em todo o perímetro do parque serão ampliadas e reformadas promovendo o uso recreativo e saudável aos cidadãos prudentinos através deste modo de deslocamento.

\section{b) Biovaletas, Jardins de Chuva - Parque do Povo}

$\mathrm{Na}$ segunda estratégia foram propostos mecanismos de apoio à drenagem para a filtragem e infiltração das águas pluviais antes de chegarem aos pontos críticos de alagamento nas áreas próximas ao Parque do Povo. Estas áreas vão atuar ainda como redutoras da velocidade da água da chuva até o córrego. São descritas na Figura 8.

Figura 8: mapa com zoom na área de implantação de instrumentos no Parque do Povo

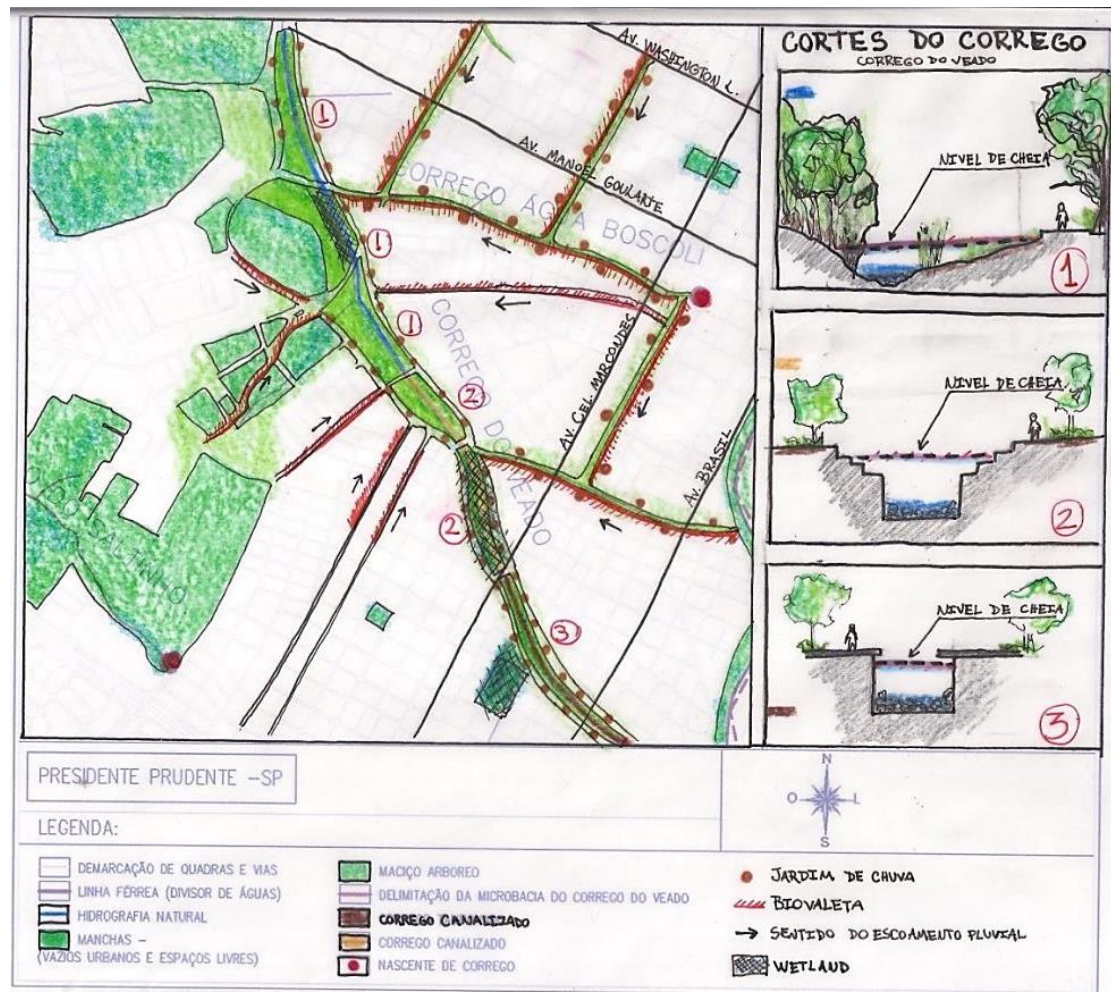

Fonte: ELABORADO PELOS AUTORES, 2016.

As biovaletas são depressões lineares preenchidas com vegetação, solo e elementos filtrantes e direcionam as águas pluviais aos sistemas de drenagem da cidade. (CORMIER E PELEGRINO, 2008.) São posicionadas, geralmente, ao longo de ruas e estacionamentos e serão adotadas em todo o perímetro do parque, canteiros centrais, calçadas do entorno do parque e nas ruas verdes. 
Os Jardins de Chuvas serão adotados nas calçadas dos lotes do entorno do Parque do Povo e nas ruas verdes, com o intuito de diminuir o escoamento superficial das águas através da infiltração gradativa ao solo. Estes são "depressões topográficas, existentes ou reafeiçoadas especialmente para receberem o escoamento da água pluvial proveniente de telhados e demais áreas" (CORMIER; PELLEGRINO, 2008, p. 128), além de serem envoltos por uma proteção lateral, de modo que realizam a filtragem e infiltração das águas provenientes de chuva.

\section{c) Arborização, Alagados Construídos e Pisos Drenantes - Parque do Povo}

A terceira estratégia se concentra no Parque do Povo e também foca na drenagem e na melhoria do microclima para a apropriação do lugar.

Propõe-se a ampliação da área arborizada do Parque do Povo tanto para conectar o parque a demais manchas, quanto para promover o controle do microclima local. Devido ao fato de o parque ser bastante utilizado, a inclusão de novas áreas vegetadas é importante para melhorar as áreas de permanência prolongada com a sombra das copas das árvores, impedindo a insolação direta em uma cidade bastante quente na maior parte do ano.

As áreas alagáveis, também conhecidas como Wetlands, possuem papel de destaque na drenagem de águas pluviais. Estas áreas, como é o exemplo campo de futebol (Figura 9) e áreas que não possuem construções fixas, são rasas, "uma camada rasa de água sobre o solo por um período suficiente para manter o solo saturado ao longo do ano e uma vegetação característica." (Pellegrino et al., 2012, p. 10). Em épocas de grandes volumes de chuvas estas áreas são alagadas, auxiliando a drenagem das águas e impedindo que estas águas invadam ruas e edificações.

Nas áreas do entorno do Parque do Povo serão adotados pisos drenantes para auxiliar a absorção de águas pluviais e auxiliar na questão do tempo do percurso destas até o córrego destamponado. Outras áreas pavimentadas também podem inserir esta melhoria, como por exemplo o estacionamento do Prudenshopping. 
Figura 9: mapa das áreas de piso drenante e ligações.

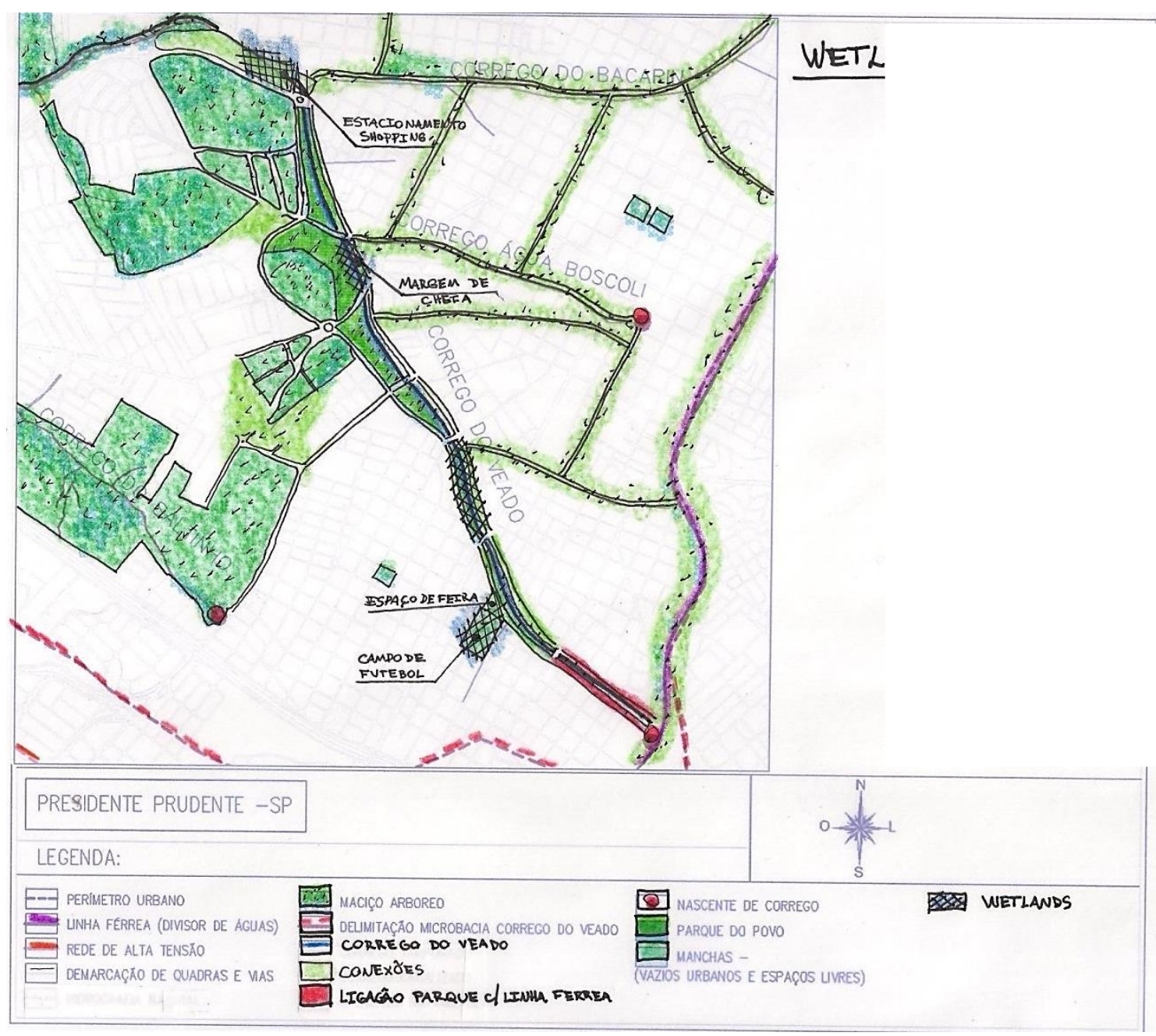

Fonte: ELABORADO PELOS AUTORES, 2016.

\section{d) Destamponamento de rios e córregos}

Este processo tem como princípio fazer a renaturalização de rios que foram tamponados e/ou canalizados na cidade, principalmente o destamponamento de uma parte do córrego do veado localizado no Parque do Povo em seu trecho mais ao norte.

Além disso, esta ação será acompanhada da reestruturação da mata ciliar, inserção de vegetação que possa filtrar sólidos que acompanham as águas pluviais e, em locais onde há placas de concreto em todo o percurso do curso d'água, estes serão retirados para que a terra e o solo possam fazer o trabalho natural. Podem ser acompanhadas de alagados construídos, para adicionar área de vazão provisória em dias de chuvas intensas.

A renaturalização dos corpos d'água da visibilidade aos rios e córregos, o que melhora a conscientização da população que, compreendendo os processos naturais como parte intrínseca da cidade, tornam-se cidadãos ambientalmente mais responsáveis. 
Em áreas onde não é possível inserir os alagados construídos, serão adotados escalonamentos e a implantação de vegetação arbustiva e aquática que possam auxiliar na filtragem dos sólidos e criar um sistema de tratamento aquífero, como mostra a Figura 14. Este sistema, de acordo com Lyle (1994, p.234), pode ser benéfico até contra a poluição do ar, pois, em grande quantidade, tais plantas conseguem filtrar o gás poluente e liberar ar ideal para a respiração.

Estas ações visam buscar de volta o conceito de deixar a natureza fazer seu trabalho através de processos naturais e biológicos. Essa "reassimilação" dos processos que foram eliminados pelo crescimento territorial desordenado pode reestruturar o local não apenas tratando das questões de enchentes, mas reestabelecendo o bom relacionamento entre os cidadãos e a natureza.

\section{CONCLUSÃO}

O Parque do Povo, em Presidente Prudente, é visto pela população como fonte de lazer, cultura e socialização. Constatou-se, porém, que o parque tem potencialidade para tornar-se uma referência para a implementação de uma estrutura ecológica na cidade.

Após a realização dos levantamentos histórico, físico-morfológico e das potencialidades locais, definiu-se quatro macro estratégias para o desenvolvimento das diretrizes projetuais que conduziriam a implantação da estrutura ecológica Tais diretrizes baseiam-se em conceitos paisagísticos e ecológicos com a integração de espaços, conectividade entre vários pontos da cidade, criação e manutenção de áreas verdes, criação de corredores verdes, arborização, resolução de questões ligadas à drenagem e a renaturalização de alguns trechos de córregos e rios.

O resultado esperado com as propostas será a implementação de uma estrutura ecológica urbana capaz de criar formas de conexão, integrar áreas, ressaltar os valores da paisagem e promover uma melhora na qualidade ambiental de da vida daquelas pessoas que vivem na cidade.

\section{AGRADECIMENTOS}

À Laís Cruz Endo que nos auxiliou na elaboração deste artigo enquanto parte integrante da disciplina de Planejamento Ambiental do Programa de Mestrado Associado em Arquitetura e Urbanismo da UEM e UEL no ano de 2016.

\section{REFERÊNCIAS BIBLIOGRÁFICAS}

ALTRAN TCBR. Plano Municipal de Drenagem Urbana de Presidente Prudente: Presidente Prudente, 2010.

BORTOLO, Carlos A. O espaço público do Parque do Povo - Presidente Prudente - SP: reflexões geográficas. GeoAtos, Presidente Prudente, n. 13, v. , p. 50-65, 2013. 


\section{da Alta Paulista}

CORMIER, Nathaniel S.; PELLEGRINO Paulo R.M. Infraestrutura verde: uma estratégia paisagística para a água urbana. Revista Paisagem Ambiente, n. 25, São Paulo, FAU-USP, p. 127-142, 2008.

DA SILVA, Nayara R.; GOUVEIA, Isabel C. M. C. Contribuições da Geomorfologia Antropogênica para análise da Bacia Hidrográfica Córrego do Veado. In: Simpósio Internacional de Águas, Solos E Geotecnologias, 1, 2015, Uberaba. Anais eletrônicos... Disponível em: http://www.sasgeo.eco.br/index.php/2015/cred/paper/viewFile/113/112>. Acesso em: 07 jul. 2016.

FERRAREZI, Andressa Mastroldi; FRANSCISCO, Arlete Maria. Morfologia urbana das áreas de fundo de vale do córrego do Veado em Presidente Prudente, SP. In: Encontro de Ensino, Pesquisa e Extensão, Presidente Prudente, 2013, Presidente Prudente.

FUNDAÇÃO INSTITUTO BRASILEIRO DE GEOGRAFIA E ESTATÍSTICA - IBGE. Dados sobre Presidente Prudente. Presidente Prudente, 2010.

FRANCISCO, Arlete M.; FERRAREZI, Andressa M.; SCATALON, Aline P.; NARIMATSU, Vanessa T. Repensando os espaços da cidade: Diretrizes Urbanísticas para Áreas de Preservação Permanente Urbanas Consolidadas. In: Seminário Nacional Sobre Áreas de Preservação Permanente em Meio Urbano e Restrições Ambientais ao Parcelamento do Solo, 3, 2014, Belém. Anais eletrônicos... Disponível em: <http://anpur.org.br/app-urbana2014/anais/ARQUIVOS/GT4-141-66-20140523001433.pdf> Acesso em: 07 jul. 2016.

FRANCISCO, Arlete M. Os desafios do planejamento urbano em áreas de fundo de vale consolidadas: o caso da microbacia do Córrego do Veado em Presidente Prudente, SP. In: Seminário Nacional Sobre Áreas de Preservação Permanente em meio Urbano: Abordagens, Conflitos e Perspectivas das Cidades Brasileiras , 2., 2012, Natal. Anais eletrônicos... $\quad$ Disponível em: http://unuhospedagem.com.br/revista/rbeur/index.php/APP/article/view/3851/3765> Acesso em: 07 jul. 2016.

FRAZILI, Layssa G. R.; ALVES,Sara L.; ALBANO, Mayara P.; MARIA, Yeda R. Análise do parque do povo como agente da reurbanização do fundo de vale, e desenvolvimento da cidade de Presidente Prudente - SP. In: Encontro de Ensino, Pesquisa e Extensão, 10, 2013, Presidente Prudente. Anais eletrônicos... Disponível em: < http://www.unoeste.br/site/enepe/2013/suplementos/area/Humanarum/Arquitetura\%20Urbanismo/ > .Acesso em: 07 jul. 2016.

LYLE, John T. Regenerative Design for Sustainable Development, New York: John Wiley \& Sons, 1994.

MENEGUETTI, Karin S. Cidade jardim, cidade sustentável. A estrutura ecológica urbana e a cidade de Maringá, Maringá: Eduem, 2009.

MCHARG, Ian L. Design with nature. New York, JohnWilley \& Sons, 1992.

PEDRO, Leda. C.; NUNES, Joao Osvaldo R. A relação entre processos morfodinâmicos e os desastres naturais: uma leitura das áreas vulneráveis a inundações e alagamentos em Presidente Prudente - SP. In: Caderno Prudentino de Geografia, Presidente Prudente, n.34, v.2, p.81-96, ago./dez.2012.

PELLEGRINO, Paulo R.M. Pode-se planejar a paisagem? In Paisagem e Ambiente: ensaios. Faculdade de Arquitetura e Urbanismo. - São Paulo: FAU, 1997, no13, dez. 2000, p. 159-180.

PELLEGRINO, et al. A paisagem da borda: uma estratégia para a condução das águas, da biodiversidade e das pessoas. In: Costa, Lucia M S A. Rios e Paisagens Urbanas em Cidades Brasileiras. Rio de Janeiro: Viana e Mosley Editora: 2006.

WARD THOMPSON, C., TRAVLOU, P. Open Space: People Space. USA and Canada, 2007, p. 220. 